\title{
The scope of application of macrocyclic polyamines beyond metal chelation
}

\author{
Pauline Lejault, ${ }^{[\mathrm{a}]}$ Katerina Duskova, ${ }^{[\mathrm{a}]}$ Claire Bernhard, ${ }^{[\mathrm{a}]}$ \\ Ibai E. Valverde, ${ }^{[\mathrm{a}]}$ Anthony Romieu, ${ }^{[\mathrm{a}]}$ and David Monchaud ${ }^{*[\mathrm{a}]}$ \\ ${ }^{\text {[a] }}$ Dr. P. Lejault, Dr. K. Duskova, Dr. C. Bernhard, Dr. I. E. Valverde, Prof. Dr. A. Romieu, Dr. D. Monchaud, Institut de Chimie Moleculaire de \\ I'Université de Bourgogne (ICMUB), CNRS UMR6302, UBFC Dijon, 9, Avenue Alain Savary, 21078 Dijon, France \\ *E-mail: ibai.valverde@u-bourgogne.fr; URL: http://www.icmub.com/en/members-en/valverde-ibai \\ *E-mail: anthony.romieu@u-bourgogne.fr $;$ URL: http://www.icmub.com/en/members-en/romieu-anthony \\ *E-mail: david.monchaud@cnrs.fr; URL: http://www.icmub.com/en/members-en/monchaud-david
}

\begin{abstract}
.
Recent advances in the use of radiometals for both imaging and therapy has spurred on the development of an original chemistry that endows radionuclide-chelating molecular cages with ever sharper physicochemical properties. Macrocyclic polyamines (MPAs) such as cyclen and DOTA are among the most frequently encountered cages for the design of new radiotracers, owing to their versatile chemistry that makes them customizable molecular tools. The idea of using MPAs for alternative purposes has recently emerged, with an eye towards benefiting from their unique topology, versatility, symmetry and water-solubility. This review summarizes strategies that have been recently implemented in which MPAs are used as multivalent molecular platforms for constructing sophisticated suprastructures that found applications in various fields, from material chemistry to chemical biology. These original approaches are invaluable in that they successfully expand the scope of applications of MPAs far beyond their restricted roles of metal chelating appendages.
\end{abstract}

Keywords: polyazamacrocycles; molecular platform; multivalency; theranostics; bioactive compounds

\section{Introduction}

Chemistry is the art of playing with complex molecular scaffolds to diversify their uses in a creative and virtually unlimited manner. The capability of chemists to modulate ad libitum the nature of chemical objects allows them for optimizing the properties of selected compounds for intended purposes (e.g., structure-activity relationship studies) or endowing chemicals with new functions, thereby opening new scopes and fields of application. Many examples of the latter approach can be cited, including the chemical modification of natural nutrients for 
cancer-directed applications, owing to the known avidity of malignant cells: for instance, the modification of glucose into 2-deoxy-2-[fluorine-18]fluoro-glucose $\left({ }^{18} \mathrm{FDG}\right)$ allows its use as an effective probe for imaging various cancers via positron emission tomography integrated with computed tomography (PET/CT); ; ${ }^{[1]}$ also, the repurposing of vitamin B9 (folic acid) as a cancerspecific carrier of drugs (e.g., maytansine, camptothecin) was thoroughly exploited in an approach referred to as small-molecule drugs conjugates (SMDCs). ${ }^{[2]}$ In fewer cases, chemists have also strived to repurpose fully synthetic compounds initially designed to fulfill precisely defined tasks, to open new chemical landscapes. In the present review, we focus on the example of macrocyclic polyamines (MPAs), ${ }^{[3]}$ which comprise a class of nitrogen-containing heterocyclic compounds that have found many applications in medicinal chemistry. ${ }^{[4]}$ The most emblematic MPA is certainly the 1,4,7,10-tetraazacyclododecane-1,4,7,10-tetraacetic acid (or DOTA) (Figure 1). ${ }^{[5]}$ This macrocycle has been thoroughly exploited for its ability to firmly chelate metal ions, thanks of the presence of 4 nitrogen atoms (embedded in the macrocyclic structure) and 4 surrounding carboxylic moieties (belonging to its 4 acetic acid pendant arms). This eightfold valency has made DOTA and DOTA-like molecules invaluable tools for multiple applications such as waste-water treatment, hydrometallurgy, and medicine. ${ }^{[3 a]}$ In the medical field, the use of metal complexes of DOTA is closely connected to molecular imaging and, increasingly, to internal radiation therapy, or radioendotherapy. Gadolinium(III) complexes of DOTA and similar macrocyclic chelators are the perfect example of successful inorganic drugs that have become commonplace in medicinal practice in the last decade. Thanks to their high relaxitivity and stability in physiological media, they have become the gold standard contrast agents for magnetic resonance imaging (MRI). ${ }^{[6]}$ However, gadolinium-based contrast agents used in the clinic are not disease-specific; as a matter of fact, the clear delineation of soft tissues they provide relies on their wide, non-specific, distribution in the body that requires the use of large amounts of metallic complex. In sharp contrast, DOTA-metal complexes can also be used for specific detection of diseases with trace amounts of imaging agent. In a classical approach, DOTA and DOTA-like molecules can be conjugated to biological vectors of interest (peptides, proteins, antibodies) prior to chelating a radiometal of interest (e.g., gallium-68, indium-111, yttrium-90, lutetium-177). ${ }^{[7]}$ The resulting, highly thermodynamically stable complexes can thus be used in vivo for diagnosis, via the use of a broad variety of imaging modalities (positron emission tomography (PET), single photon emission computed tomography (SPECT), Cerenkov luminescence imaging (CLI), 
etc.), multimodality approaches, ${ }^{[8]}$ or therapeutic purposes, through radioendotherapy using electron ( $\beta^{-}$decay)- or alpha $(\alpha)$-particle emitting radiometals, or both (the so-called theranostic approach). ${ }^{[9]}$ The unique complexation properties of DOTA and, beyond this, of many MPAs, and their medical uses thereof, are regularly covered by authoritative reviews the reader is invited to refer to. ${ }^{[3 a, 4,6,8,10]}$
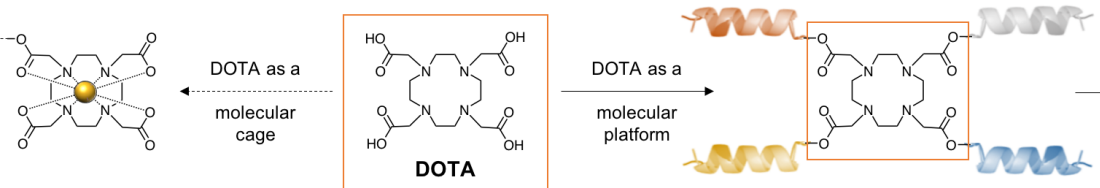

Supramolecular assemblies

- Drug multivalency (symmetrical)

$\rightarrow$ Drugs heteromultimers (non-symmetrical)

Four-fold molecular devices

Multifunctional conjugates

Figure 1. Schematic representation of the uses of DOTA either as molecular cage for chelating metals (left panel) or as platform to assemble multivalent molecular tools (right panel), which is the key topic of the review.

Here, we focus on original strategies that have been devised and implemented over the past few years to exploit another, lesser-known aspect of MPAs, unrelated to metal chelation. DOTA encodes an interesting topological information, due to the programmable positioning of its four, easily derivatizable acetic acid arms, which has not received the attention it deserves. Beyond its chemical stability, inherent polarity and marked aqueous solubility, DOTA can be used as a molecular platform to allow for assembling up to four compounds of interest in a single scaffold, and possibly modulate the physico-chemical properties of the resulting multi-component molecular architecture (Figure 1). This approach has led to the design, synthesis and studies of original, highly functionalized MPAs, which can be either symmetrical (fourfold derivatization) or not (tailored derivatization for endowing MPAs with multiple distinct molecular fragments and functionalities). As further detailed in the next sections, these exquisite molecular tools have found applications in various chemical fields, from soft matter to chemical biology. This review is not mainly dedicated to the synthetic aspects related to MPAs since the vast majority of molecular tools showed below are readily prepared through conventional $\mathrm{N}$-alkylation and/or peptide-like coupling reactions, taking advantage of well-established protecting group manipulations. HPLC purifications are often privileged for their isolation in pure form (often as trifluoroacetic acid salts), due to the marked polarity and large molecular size of these sophisticated multivalent conjugates. Nevertheless, for some examples of functionalized MPAs, more specific information related to their synthesis/purification which we consider to be relevant for the reader will be provided throughout the text. 


\section{Symmetrical MPAs}

Full- $N$-functionalization of readily available tetraazacycloalkanes (i.e., cyclam, cyclen and TACN, vide infra) with the same molecular arm may be regarded as one of the most straightforward and simple way to access to multivalent compounds with specific structural features and tailored properties. It is therefore not surprising that the first applications of MPAs beyond metal chelation were based on use of such symmetrical architectures.

\subsection{Soft matter and chirality sensing}

In the early 2000s, Michinobu, Tsukube and co-workers have synthesized a DOTA conjugated to four chiral cholesterol units (one per arm), through tetra- $N$-alkylation of $1,4,7,10$ tetraazacyclododecane (or cyclen) with cholesterol chloroacetate (1, Figure 2). ${ }^{[11]}$ This derivative self-assembles in aqueous ethanol solutions (20-30\%) as chiral aggregates (critical aggregation concentration: $4 \mu \mathrm{M}$ ), due to the intrinsic chirality of the cholesterol unit that is spread over the whole supramolecular structure upon self-association.

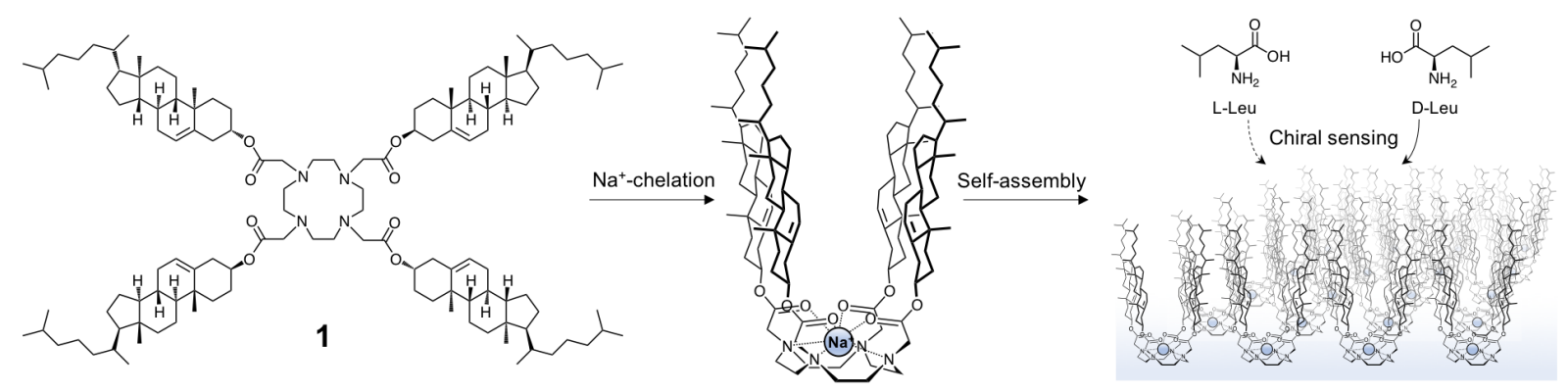

Figure 2. Structure of the cholesterol-armed cyclen designed by Michinobu, Tsukube and co-workers. Formation of its octadentate $\mathrm{Na}^{+}$complex and subsequent self-assembly to chiral host monolayer (at the interface airwater) for mechanical control of enantioselectivity of amino acid recognition.

This asymmetry was exploited to sense amino acids fluorescently labeled with an environment-sensitive fluorophore, namely dansyl, in solution, discriminating for instance between dansyl-L-leucine and dansyl-D-leucine by both the fluorescence enhancements (triggered by the hydrophobic pocket provided by the cholesterol units, 6.5-versus 4.9-fold, respectively, i.e., 1.3-fold difference) and the blue-shifts of emission maxima (from 532 to 505 and $507 \mathrm{~nm}$, respectively). ${ }^{[12]}$ Furthermore, at the air-water interface, compound 1 leads to the formation of a stable monolayer (molecular area: $1.6 \mathrm{~nm}^{2}$; collapse pressure: $50 \mathrm{mM} . \mathrm{m}^{-1}$ ), owing to its resolutely amphiphilic nature (hydrophobic cholesterol versus hydrophilic MPA on the other hand) (Figure 2). The resulting chiral monolayer was exploited to sense unlabeled amino acids, discriminating L-leucine versus D-leucine by their binding constants $(K)$ measured 
via surface pressure $(\pi-A)$ isotherm measurements $\left(K=85.2\right.$ versus $1063.0 \mathrm{M}^{-1}$, respectively, i.e., 12.5-fold difference at $1 \mathrm{mM} . \mathrm{m}^{-1}$ pressure). ${ }^{[13]}$ Of note, in these investigations, the presence of $\mathrm{Na}^{+}$ion is mandatory, as a trigger for the chiral folding the cholesterol-armed DOTA via its octacoordination at the very heart of the conjugate.

\subsection{Medicinal chemistry and multivalency}

A possible way to improve the efficiency of therapeutics is to assemble multiple units in a same scaffold (the so-called multivalency approach) ${ }^{[14]}$ via covalent linking to a molecular platform. Recent studies seem to indicate that ligand hetero- or homo-multimerization provides increase in half-life in vivo, circulation time and receptor avidity. Thorough studies were performed with cyclic arginine-glycine-aspartic acid (RGD) peptides c(RGDfK) or $c\left(\right.$ RGDyK), which targets integrin $\alpha_{\mathrm{v}} \beta_{3}{ }^{[15]}$ among others. This receptor affects tumor growth, local invasiveness, metastatic potential and is lowly expressed on the surface of nonmalignant cells while being overexpressed on tumor cells in need of neovasculature. Such expression profile constitutes a unique therapeutic target. ${ }^{[16]}$ Furthermore, it has been demonstrated that integrin heterodimers are prone to receptor clustering upon cell activation, resulting in increased ligand avidity. ${ }^{[17]}$ Thus, strategies of multimerization of $c($ RGDfK) have already been implemented successfully, mostly through the use of trifunctional amino acid-based platforms. As an example, the glutamic acid (E) was used to synthesize both the dimer $E[c(R G D f K)]_{2}$ and the tetramer $E\left[E[c(R G D f K)]_{2}\right]_{2}$ (in which two dimers are linked via an additional glutamic acid unit). ${ }^{[18]}$ Both derivatives show improved integrin binding affinity and cellular uptake, lending credence to this strategy. Similarly, Boturyn and co-workers reported on the synthesis of a Cy5.0-labeled c(RGDfK) tetramer based on a cyclic decapeptide scaffold (RAFT) that displayed improved selectivity for tumor xenografts overexpressing the $\alpha_{v} \beta_{3}$ receptor in comparison with its monomeric counterpart. ${ }^{[19]}$ Cheng and co-workers further explored it, exploiting the unique versatility of the DOTA platform to construct monomeric to tetrameric c(RGDfK) conjugates (DOTA-P1, -P2, -P3 and -P4, respectively, with P for peptide) (Figure 3). ${ }^{[20]}$ Of note, the easy-to-implement synthetic protocol described here, based on the aminolysis of $\mathrm{N}$-hydroxysulfosuccinimidyl ester of DOTA (DOTA-sulfo-NHS) by fully deprotected peptide $c(R G D y K)$ in aqueous buffer, was devised to rapidly obtain RGD multimers. The four compounds were obtained during a single coupling reaction conducted with a large excess of DOTA-sulfo-NHS, and recovered in a pure form by reversed-phase HPLC 
purification, but neither in large amounts nor in optimized yields. This study confirmed the better integrin affinity of DOTA-Ps, evaluated through competitive binding assays against ${ }^{125}$ Iechistatin $\left(\mathrm{IC}_{50}=380,37\right.$ and $13 \mathrm{nM}$ for DOTA-P1, -P2 and -P3, respectively), but also highlighted that the DOTA tetra-functionalization might be chemically challenging especially via amidation reactions performed in aqueous buffer ( $\mathrm{pH}$ 8.5-9.0), given that DOTA-P4 was not isolated in quantities suited to in vitro evaluations.

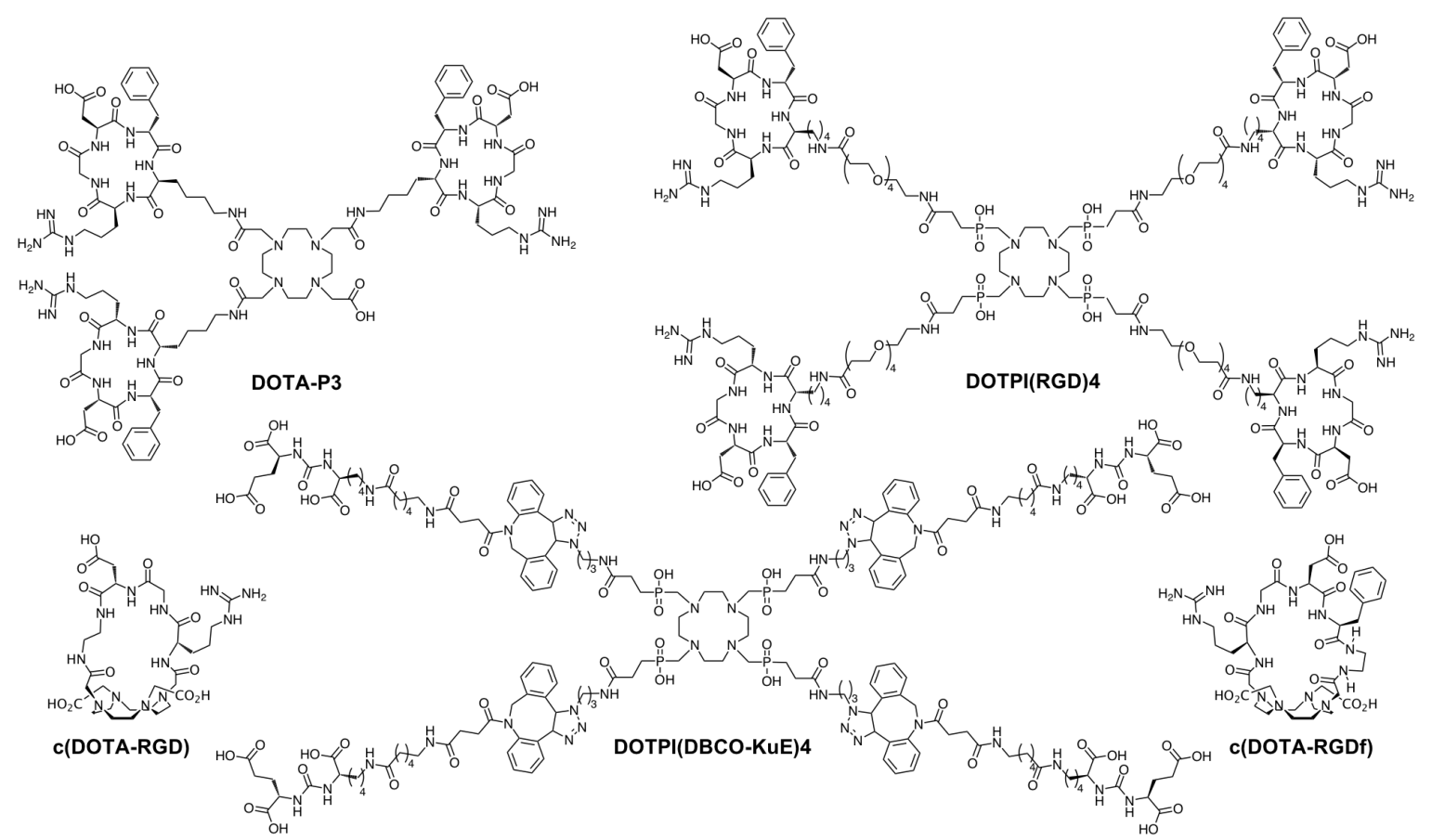

Figure 3. Selected examples of macrocyclic chelator-assembled RGD (upper panel) and KuE (center, lower panel) multimers for tumor targeting through PET imaging, as well as merged DOTA and RGD scaffold (both sides, lower panel). Counter-ions (mostly TFA) not shown.

A further step was taken towards the optimization of the chemical nature of DOTA/RGD conjugates by Sun, Leon-Rodriguez and co-workers, merging the DOTA and RGD/RGDf structures in a single scaffold, with the hope of decreasing conformational variability. ${ }^{[21]}$ However, the resulting cyclic c(DOTA-RGD) and c(DOTA-RGDf) (Figure 3) displayed no real improvements, with a lower $\alpha_{\mathrm{v}} \beta_{3}$ binding in vitro than the RGD control $\left(\mathrm{IC}_{50}=4.7\right.$ and $20.4 \mathrm{nM}$ for c(DOTA-RGD) and c(DOTA-RGDf), respectively versus $6.7 \mathrm{nM}$ for RGDf) and lower tumor uptake in vivo (when labelled with ${ }^{177} \mathrm{Lu}$ and ${ }^{64} \mathrm{Cu}$ ). Notni and co-workers developed an alternative strategy to tackle DOTA derivatization issues, replacing the DOTA platform by the more reactive 1,4,7,10-tetraazacyclododecane-1,4,7,10-tetramethylenephosphinic acid (DOTPI). The tetra-functionalization of DOTPI was performed through the sequential coupling of amino acid $\mathrm{PEG}_{4}$ linkers (DOTPI $\left(\mathrm{PEG}_{4}\right) \mathbf{4}$, isolated yield $=38 \%$ ) and fully protected 
$c($ RGDfK)(Pbf,tBu) peptide followed by TFA treatment to remove protecting groups (DOTPI(RGD)4, isolated yield $=68 \%$ ) (Figure 3). ${ }^{[22]}$ The use of the peptide coupling reagent $O$ (7-azabenzotriazol-1-yl)- $N, N, N^{\prime}, N^{\prime}$-tetramethyluronium hexafluorophosphate (HATU) allows for achieving chemoselective amidation reactions without protection of the phosphinate moieties, making the synthesis of DOTPI(RGD)4 particularly straightforward. This conjugate displayed a higher integrin affinity, evaluated by ELISA using cilengitide as internal standard, with $\mathrm{IC}_{50}=1330$ and $109 \mathrm{pM}$ for monomeric $\mathrm{c}(\mathrm{RGDfK})$ and DOTPI(RGD)4, respectively (i.e., 12.2-fold difference). The same research group also explored the grafting of four prostatespecific membrane antigen (PSMA) inhibitors KuE (Lys-urea-Glu) to DOTPI platform via click chemistry (both copper-catalyzed and copper-free azide-alkyne cycloadditions, CuAAC ${ }^{[23]}$ and SPAAC, ${ }^{[24]}$ respectively, to assess whether $\mathrm{Cu}(I 1)$ precatalyst can be used or not in the context of molecular platform with marked copper chelating ability). PSMA, being a membrane-bound zinc hydrolase overexpressed in prostate cancers, is a high-value target (being subjected to 190 clinical trials, 23 of them being currently active). ${ }^{[25]}$ Obtained multimers DOTPI(Trz-KuE)4 and DOTPI(DBCO-KuE)4 (Trz for triazole, DBCO for dibenzocyclooctyne) (Figure 3) display a higher PSMA affinity than monomeric KuE, along with high tumor uptake and blood clearance. ${ }^{[26]}$ Of note, in these investigations, radiometals were subsequently sequestered at the very heart of both DOTA-Ps and DOTPIs to allow for tracking biodistribution of the resulting complexes in vivo through nuclear imaging.

\subsection{Chemical genetics and biomimicry}

The fourfold symmetry of DOTA was also exploited for the construction of chemicals targeting fourfold symmetrical targets. Quadruplex-DNA and RNA (or G4-DNA and G4-RNA, respectively) fold from guanine (G)-rich nucleic acid sequences. ${ }^{[27]}$ The structure of this higherorder DNA/RNA architecture is rather peculiar, given that its stability arises from the formation of fourfold symmetrical G-quartets (i.e., coplanar and cyclic arrangement of four guanines held together via 8 hydrogen bonds) that self-stack to form stable DNA/RNA structures (Figure 4). Quadruplexes (or G4s) are now recognized as key players in genetics, owing to their involvement in critical cellular events, chief among them replication and transcription. ${ }^{[28]}$ Their targeting of G4s by ad hoc chemicals (G4-ligands) has attracted considerable attention, notably for gaining control over the cellular processes they are 
involved in. Hundreds of candidates have been studied as G4-interacting compounds, the overwhelming majority of them binding to the accessible external G-quartet of G4s. ${ }^{[29]}$
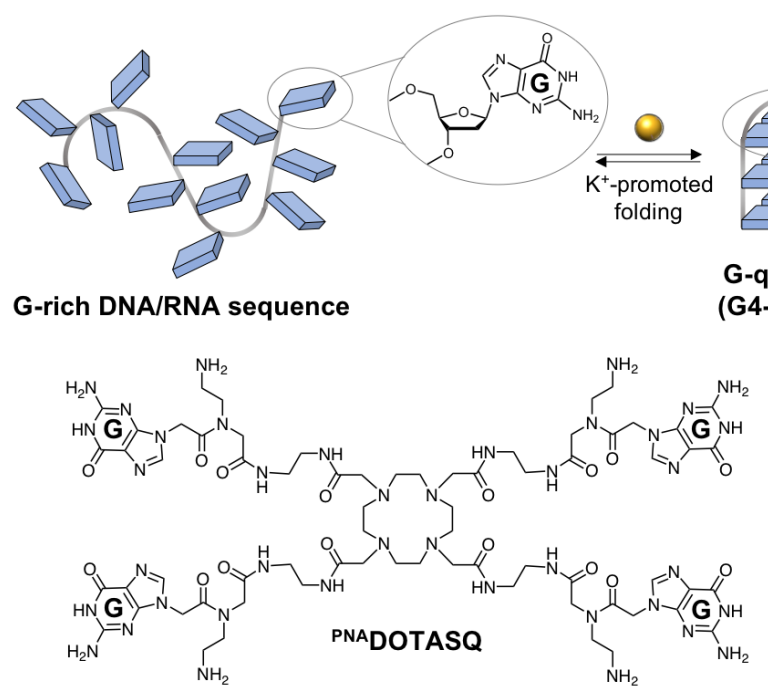
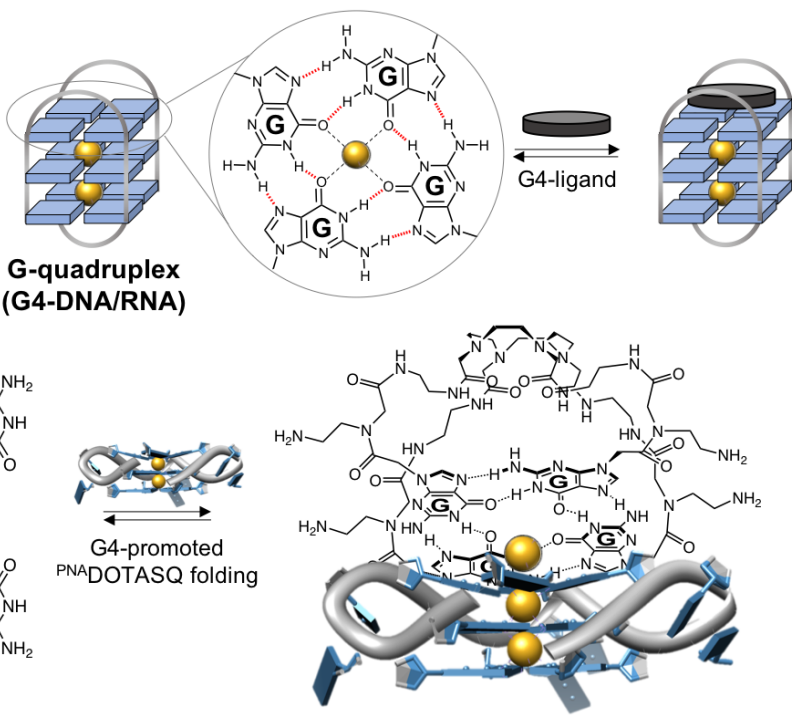

Figure 4. Schematic representation of a G-quadruplex structure (with an emphasis on the chemical structure of both guanine and G-quartet) and its interaction with a G4-ligand (upper panel). Adapted from ref. ${ }^{[30 \mathrm{~b}]}$ The smart G-quadruplex ligand ${ }^{\mathrm{PNA}}$ DOTASQ, under its 'open' (left) and 'closed' conformations (right), the latter being triggered by its interaction with a G-quadruplex only.

Given the fourfold symmetry of this privileged binding site, DOTA-based G4-ligands were designed. A synthetic guanine was inserted on each DOTA arm to allow the resulting compound for forming an intramolecular synthetic G-quartet. This compound named DOTASQ (for DOTA-templated synthetic G-quartet) uniquely interacts with G4 according to a biomimetic process (i.e., the self-recognition of two G-quartets, one from the ligand and one from the G4), thus being the first prototype of biomimetic G4-ligand. ${ }^{[30]}$ A second generation of DOTASQ was reported, in which the simple guanines of DOTASQ were changed for peptidic nucleic acid (PNA)-guanine monomers, in which the presence of protonable amine side-arms

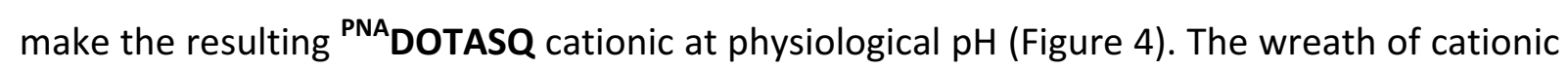
charges around its intramolecular G-quartet governs and improves its interaction with native G-quartets (surrounded by negative charges from the phosphodiester linkages). ${ }^{[31]}$

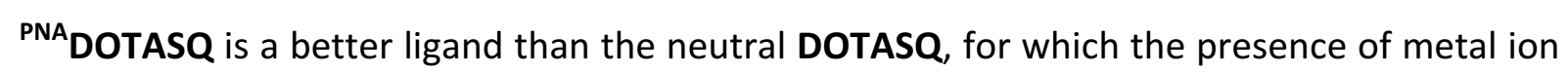
(terbium, $\mathrm{Tb}^{3+}$ ) was mandatory to trigger the intramolecular G-quartet folding. This was evaluated via fluorescence resonance energy transfer (FRET)-melting assay, with $\Delta T_{1 / 2}=12.5$

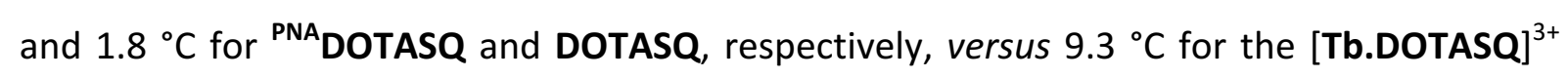
complex. The equilibrium between the 'open' (guanines are free) and 'closed' (guanines are

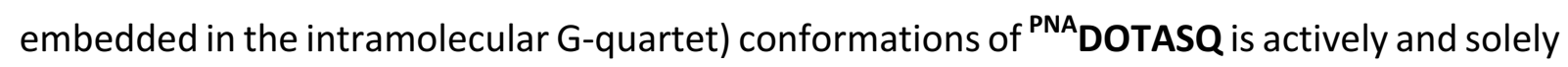


driven by its interaction with G4s (demonstrated by NMR), thus being the first prototype of smart G4-ligand.

\section{Non-symmetrical MPAs}

A greater demand for multifunctional biomolecular devices, especially for applications in chemical biology, drug discovery and theranostics, has also led chemists to explore multiple functionalization of MPAs with different entities via sophisticated synthetic strategies. Some examples illustrating the use of DOTA derivatives as heteromultifunctional scaffolds will be discussed in the next sections.

\subsection{MPAs with multiple functionalities}

To further exploit the unique opportunity offered by MPA-based multimerization, Schultz, Nazare and co-workers described an elegant chemical strategy in which they insert on a DOTA platform up to three active biomolecules (collagen targeting peptides) along with a fluorescent reporter (i.e., the near-infrared fluorescent Cy5.5 dye). ${ }^{[32]}$ The use of DOTA mono, di- or tri-tert-butyl ester in combination with Fmoc/Boc protecting group strategy enables a facile and effective synthesis of these fluorescently-labeled multi-peptide conjugates through sequential peptide coupling-type coupling reactions performed in solution (i.e., with DMF as solvent). Small-molecules targeting diseased cartilaginous tissues are indeed scrutinized as promising molecular tools to remediate cartilage breakdown, responsible for osteoarthritis. ${ }^{[33]}$ The targeting of one of the cartilage constituents, here the type II collagen, by $\mathrm{N}$-acetylWYRGRL (Ac-Trp-Tyr-Arg-Gly-Arg-Leu-OH) peptides being previously established, this study aimed at showing that the more peptidic arms, the better the cartilage targeting, investigating both (AC-WYRGRL) ${ }_{1}$-DOTA-Cy5.5 (or 1TP, T for targeting peptide, P for probe) and (ACWYRGRL) ${ }_{3}$-DOTA-Cy5.5 (or 3TP) (Figure 5). Optical imaging investigations demonstrated that the accumulation of the conjugates in cartilage increased as a function of the number of peptides (11.2-fold and 36.6-fold increase of fluorescence for 1TP and 3TP, respectively, versus non-peptide but Cy5.5-labeled DOTA control). Drug multivalency thus improved cartilage targeting, penetration and retention. The versatility of this approach was further demonstrated via the conjugation of both Ac-WYRGRL and pepstatin A (JVV-Sta-A-Sta or IvaVal-Val-Sta-Ala-Sta, Iva for isovaleryl, Sta for statyl, with statine (3S,4S)-4-amino-3-hydroxy-6methylheptanoic acid) on DOTA. Pepstatin $A$ is a known inhibitor of cathepsin $D_{1}^{[33]}$ responsible for glycan loss-mediated cartilage degradation. The resulting conjugates comprise 
either 1 Ac-WYRGRL and 1 pepstatin A (1P1I, P for peptide, I for inhibitor), 1 Ac-WYRGRL and 3 pepstatin A (1P3I) or 3 Ac-WYRGRL and 1 pepstatin A (3P1I) (Figure 5). Though less active in vitro $\left(\mathrm{IC}_{50}=6.2\right.$ and $3.3 \mathrm{nM}$ for $\mathbf{1 P 1}$ and $3 \mathrm{P} 1 \mathrm{I}$, respectively, versus $1.4 \mathrm{nM}$ for free pepstatin $\mathrm{A}$; 1P3I being insoluble in the condition of the assay), these conjugates were found more active than pepstatin A in ex vivo experiments performed with cartilage explants, notably 3P1I that maintains a notable inhibitory activity (18\%) after $48 \mathrm{~h}$. These results demonstrate that peptide ligand multimerization improves the efficiency of cartilage targeting and, beyond this, the strategic interest of DOTA as drug carrier platform.

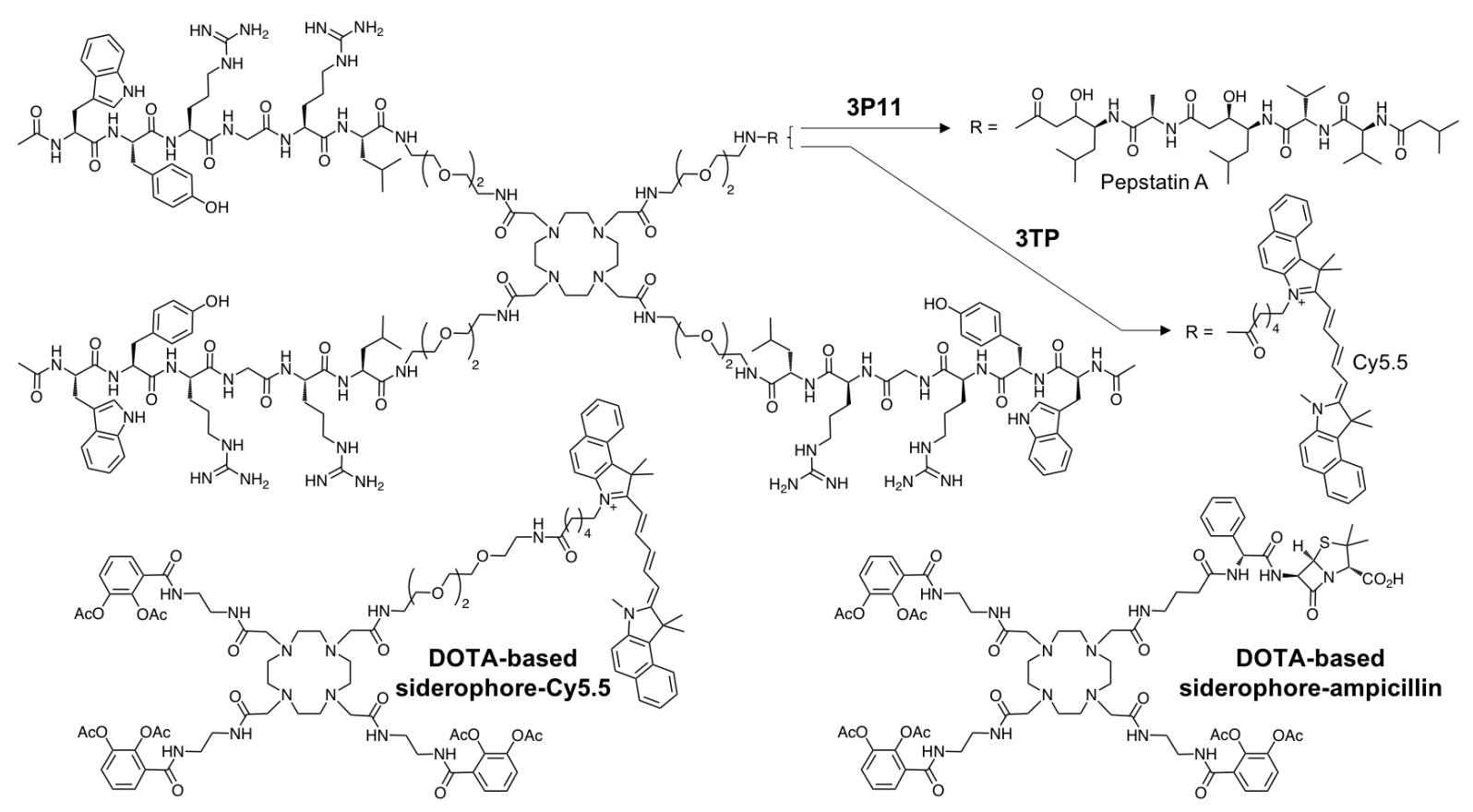

Figure 5. Selected examples of multivalent drug carrier platforms based on DOTA: cartilage-targeting carrier conjugated to pepstatin A (3P11) or the fluorescent Cy5.5 dye (3TP) (upper panels), and acetyl prodrug of DOTAbased analog of enterobactin conjugated to the fluorescent Cy5.5 dye or the $\beta$-lactam antibiotics ampicillin (lower panels). Counter-ions (mostly TFA) not shown.

This approach was further exploited by Brönstrup and co-workers through the use of multivalent siderophore-DOTA conjugates for targeting bacteria. ${ }^{[34]}$ The introduction of three $O$-acetyl-2,3-dihydroxybenzoic acid units on the DOTA scaffold via amide linkages made the resulting conjugate capable of capturing and firmly chelating iron (i.e., acting as a siderophore after hydrolysis of its acetate moieties by bacterial esterases and may be regarded as an enterobactin analog). ${ }^{[35]}$ This strategy is therapeutically efficient given that coupling antibiotic agents with iron-binding motif drives conjugated xenosiderophores within bacteria through their iron transportation machinery. Here, the fourfold valency of DOTA allows for introducing 
an additional functionality (Figure 5): either the antibiotic ampicillin that results in a conjugate with an antibacterial activity lower against wild-type $E$. Coli $\left(\mathrm{IC}_{50}=30.2\right.$ versus $4.3 \mu \mathrm{M}$ for ampicillin used as control) but enhanced against enterobactin receptor-deficient mutants (IC 50 $=3.3$ versus $6.2 \mu \mathrm{M}$ for ampicillin), implying that DOTA is recognized as iron carrier that may enter bacteria via various transporters, which brings significant therapeutic dividends for tackling resistance issues. Additionally, the tris-siderophore-substituted DOTA was labeled with a Cy5.5 fluorophore leading to the successful detection of bacterial infection in vivo through optical imaging in a group of mice subcutaneously injected with $P$. aeruginosa (here, at $20 \mu \mathrm{g} . \mathrm{kg}^{-1}$ via a monitoring performed between 0.6-24 h). Again, these results highlight the strategic interest of DOTA as multivalent drug carrier platform.
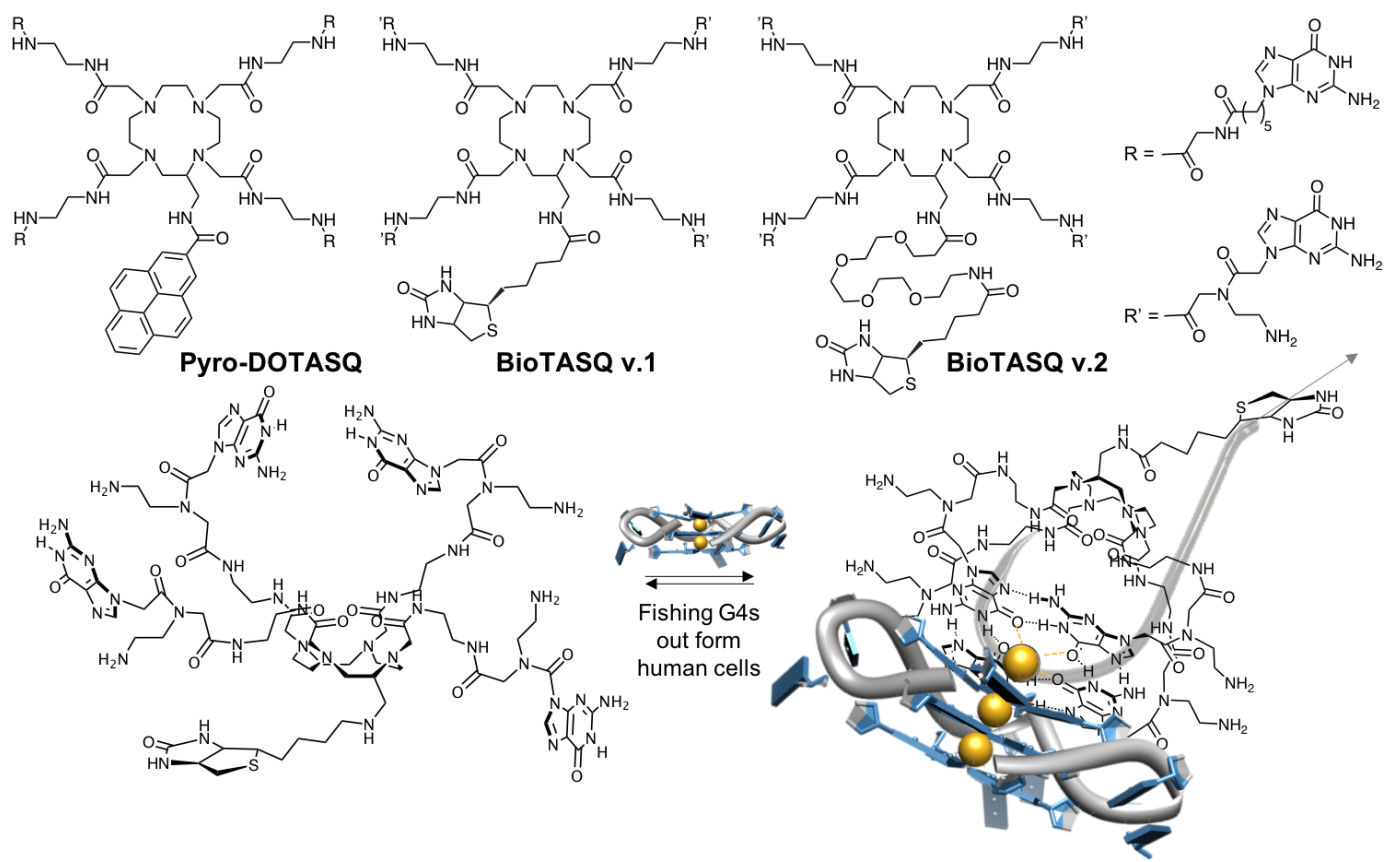

Figure 6. Examples of biomimetic (Pyro-DOTASQ) and smart G-quadruplex ligands (BioTASQs) based on the $C$ functionalized DOTA platform (upper panel). Schematic representation of the use of BioTASQ to fish Gquadruplexes out from human cells via an affinity pull-down strategy (lower panel). Adapted from ref. ${ }^{[38]}$ copyright (2019), with permission from Oxford University Press.

\subsection{C-functionalization of MPAs}

For some applications, the chemical differentiation and orthogonal derivatization of the four acetic acid pendant arms of a DOTA platform is not relevant or suited to obtain targeted multicomponent conjugates. In this context, another way for introducing an additional functionality on DOTA, while keeping the global symmetry of the conjugate, is to chemically modify the DOTA scaffold itself. The $C$-functionalization of cyclen has been reported as a way to introduce an aminomethyl appendage on cyclen poised to be conjugated through conventional peptide- 
type coupling chemistry. ${ }^{[36]}$ This approach was exploited to insert a pyrene moiety on DOTASQ (vide supra) for making the resulting terbium complex [Tb.Pyro-DOTASQ] ${ }^{3+}$ (Figure 6), a luminescent ligand readily immobilizable on graphene surface. ${ }^{[37]}$ The insertion of pyrene was found to improve the G4-binding properties of the complex (evaluated via FRET-melting assay, with $\Delta \mathrm{T}_{1 / 2}=15.3$ and $9.3^{\circ} \mathrm{C}$ for [Tb.Pyro-DOTASQ] ${ }^{3+}$ and [Tb.DOTASQ] ${ }^{3+}$, respectively), likely due to its steric hindrance that might facilitate the spatial orientation of the four guanine arms on the same side of the DOTA scaffold. Upon irradiation at $308 \mathrm{~nm}$, the complex was found to efficiently sense the presence of G4s (with a 4-fold enhancement of the luminescence signal at $545 \mathrm{~nm}$ in presence of 10 molar equivalents $\mathrm{G} 4 \mathrm{~s}$, versus no modifications with duplex-DNA). The $C$-functionalization strategy was also implemented to add a biotin tag on DOTASQ, in order to allow the resulting BioTASQ for being used as a bait for capturing G4-DNA/RNA from human cells. ${ }^{[38]}$ Thanks to the well-known biotin/streptavidin affinity purification system, BioTASQ efficiently pulls down G4-RNA from living human cells, prior to sequencing for characterizing isolated G4-RNA sequences. Two biotin appendages were introduced (biotin per se, and PEG 4 -biotin, for BioTASQ v.1 and v.2, respectively, Figure 6), which in both cases decreases its affinity of $\mathrm{G} 4$ in vitro (evaluated via FRET-melting assay, with $\Delta \mathrm{T}_{1 / 2}=2.4$ and 0.4

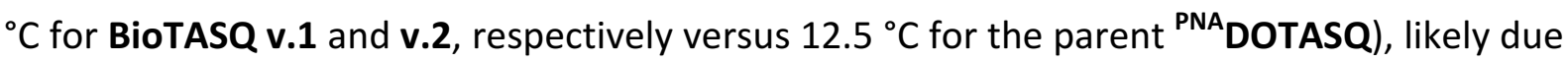
to an intramolecular interaction between biotin and guanine moieties. The interaction with streptavidin-coated particles allows for tackling this issue (hijacking biotin) and makes BioTASQs capture efficiently G4s (G4-RNA precipitation, G4RP) subsequently identified by sequencing (G4RP-seq protocols). ${ }^{[39]}$ This technique, derived from the Chem-seq method, ${ }^{[40]}$ has not only allowed for confirming the transient existence of $\mathrm{G} 4 \mathrm{~s}$ in functional cells (highlighting their transient formation) but also for assessing the variations in G4 landscapes upon G4-ligand treatment.

\subsection{MPAs and higher-order chemical architectures}

MPAs were also used as platforms for building higher-scale suprastructures. As an example, Yu and co-workers synthesized cyclen-based cationic lipopolymers to serve as gene vectors. ${ }^{[41]}$ The intracyclic nitrogen atoms of the cyclen were used as hydrophilic headgroups whereas the acetate arms were conjugated to small lipids via ring-opening polymerization to build amphiphilic polymers (Figure 7). They display enhanced transfection efficiency (TE) and cellular uptake, notably thanks to the "proton sponge effect" ${ }^{142]}$ that is based on the 
protonation of the gene vector within the endosomes, which favors osmotic swelling and endosomal rupture to deliver the nucleic acid partners. The chemical nature of cyclen allows for the formation of linear polymers only, with a rather low degree of polymerization ( $\mathrm{MW}<$ 5000). These amphiphilic compounds self-assemble in solution into nanometer-size micellar structures (critical micelle concentration: $0.2 \mathrm{mg} / \mathrm{mL}$; average micelle size $=300 \mathrm{~nm}$ ). These polymers, which displayed low intrinsic toxicity, were used to condensate DNA (with a 2.8 polymer/DNA weight ratio, here the pGL-3 plasmid coding for luciferase as reported gene) and transfect cancer cells with a higher TE (14-fold) than that of commercially available transfection agents (polyethylenimine, PEI). ${ }^{[3 a]}$ Of note, the MPA-based gene delivery approach was thoroughly investigated with cyclen $^{[43]}$ but also with alternative MPAs such as [12]aneN ${ }_{3}{ }^{[44]}$ or $\mathrm{TACN}^{[45]}$ highlighting again the great versatility of this family of macrocycles.

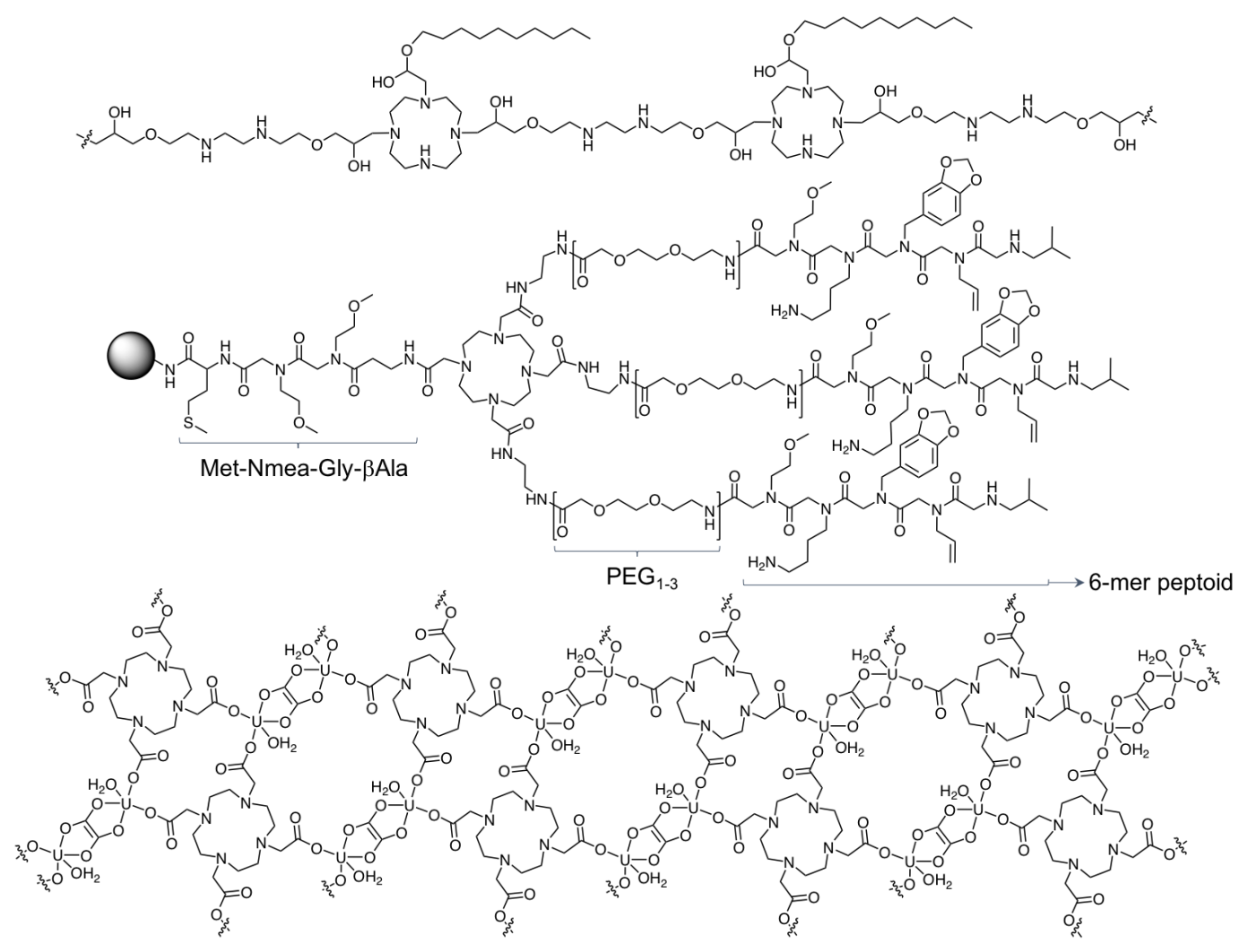

Figure 7. Selected examples of cyclen-based high-order chemical architectures: amphiphilic polymer for gene delivery (upper panel); on-bead structure of tri-peptoid-DOTA molecule for screening and discovering novel and multivalent theranostic agents (central panel); and uranyl-organic framework in which DOTA acts as a "square assembler" (lower panel).

Another approach was reported by Udugamasooriya and co-workers in which they use DOTA to build on-bead combinatorial libraries of DOTA-peptoid conjugates, ${ }^{[46]}$ aimed at being used for screening and discovering novel and multivalent theranostic agents. To this end, one arm 
of the DOTA was used to immobilize the construct on TentaGel beads ( $300 \mu \mathrm{M}$ diameter) via a short Met-(Nmea-Gly)-ßAla linker (Met for methionine, Nmea-Gly for $\mathrm{N}$-(2methoxyethyl)glycine and $\beta$ Ala for $\beta$-alanine), the three other arms used to introduce 6-mer peptoid units through PEG-type linkers of various lengths (Figure 7). This approach, so called of split-pool synthesis, allowed for generating a library that amounts to $>150000$ compounds in a straightforward and efficient manner also exploiting the effectiveness of microwave (MW)-assisted solid-phase peptide synthesis protocols (overall yields $>80 \%$ ). Hudson and coworkers also thoroughly investigated the chemistry of MPA-peptide conjugates, developing a straightforward access via either MPA peralkylation strategies implemented with cyclen to produce DOTA-type conjugates ${ }^{[47]}$ (but also TACN and cyclam derivatives) ${ }^{[48]}$ or click chemistry approach performed with non-symmetrical DOTA derivatives and based on the prior incorporation of a terminal alkyne into the side-chain of tyrosine residue(s) (i.e., propargyl ether moiety). ${ }^{[49]}$ Finally, DOTA was also used, yet more anecdotally, as a "square assembler" in metal-organic frameworks (MOF): ${ }^{[50]}$ in this assembly, DOTA does not chelate metal within its cavity but is surrounded by four uranyl U(IV) cations $\left(\mathrm{UO}_{2}{ }^{2+}\right)$, likely due to the excess of metal (i.e., 4 mol. equiv.), which connected the matrix via oxalato bridges (Figure 7). The obtained crystal structure confirmed the square conformation of DOTA, which provides a MOF with $5 \times 8$ Å pores. Cyclen was also used to assemble suprastructures such as carbon dots (CDs) via a $\mathrm{MW}$-assisted condensation reaction with citric acid followed by a carbonization step. ${ }^{[51]}$ The obtained blue-emitting CDs were further used to coordinate europium $\left(\mathrm{Eu}^{3+}\right)$ ions to construct a ratiometric fluorescent probe for tetracyclin detection.

\section{Other types of MPA platforms}

While most of the examples of multivalent bioconjugates reported in the literature (and discussed above) are built around a cyclen platform, the use of other MPAs has also been exploited. They offer different topological and functional possibilities and their unique chemistry is suited to construct original molecular devices with new applications, notably in the chemical biology area.

\subsection{Sarcophagine, NOTA and RGD multimerization}

Other MPAs than the cyclen/DOTA system were used as molecular platforms: Li, Conti and coworkers have for instance developed a multifunctional sarcophagine template, aimed at tackling in vivo stability of the ${ }^{64} \mathrm{Cu} / \mathrm{MPA}$ complexes. The two pendant amine groups of this 
bicyclic MPA were derivatized to allow for the grafting of two $c(R G D y C)$ units via maleimide (Mal) linkers. The copper complexes of the resulting $\mathbf{M a l}_{\mathbf{2}} \mathrm{Sar}_{\mathbf{R}} \mathbf{G D}_{\mathbf{2}}$ (Figure 8) showed improved in vivo stability and better kinetics as compared to DOTA-c(RGDyC) conjugates in human glioma tumors. ${ }^{[52]}$
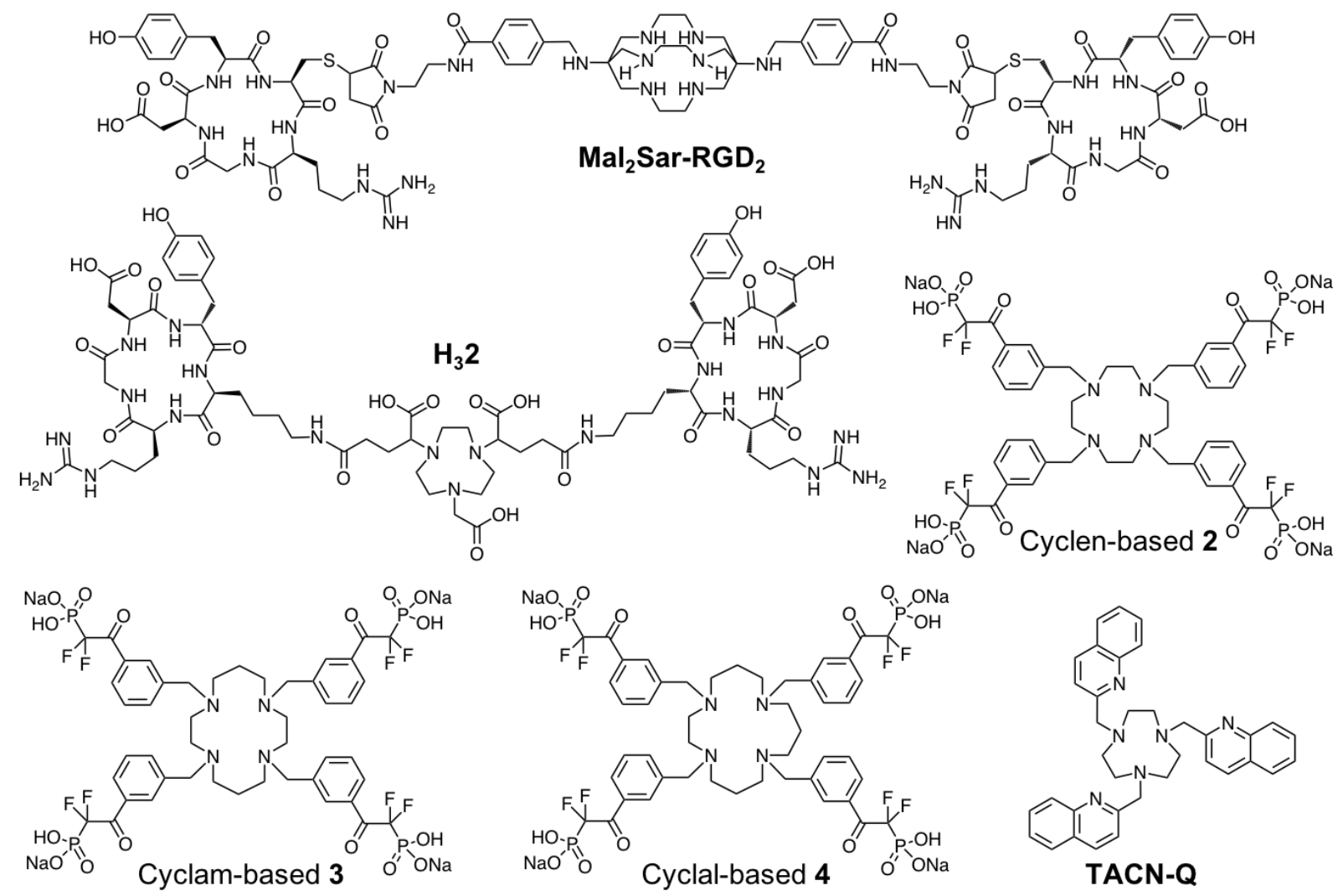

Figure 8. Selected examples of mulitvalent bioconjugates based on different MPAs (including sarcophagine, TACN, cyclen, cyclam and cyclal) and phosphonate derivatives of tetraazamacrocycles used as inhibitors of protein tyrosine phopshatases).

A similar $\mathrm{c}(\mathrm{RGDyC})$ multimerization approach was followed by Sun and co-workers using a 1,4,7-triazacyclonane-1,4,7-triacetic acid (or NOTA) platform, surrounded by 1 to $3 c(R G D y C)$ units (named $\mathrm{H}_{3} \mathbf{1}, \mathrm{H}_{3} \mathbf{2}$ and $\mathrm{H}_{3} \mathbf{3}$, respectively). ${ }^{[53]}$ The multimeric conjugates were found to have better $\alpha_{v} \beta_{3}$ binding in vitro than the monomeric control $\left(\mathrm{IC}_{50}=171,44\right.$ and $15 \mathrm{nM}$ for $\mathrm{H}_{3} \mathbf{1}, \mathrm{H}_{3} \mathbf{2}$ and $\mathrm{H}_{3} \mathbf{3}$, respectively, Figure 8) and the $\mathrm{c}(\mathrm{RGDyC})$ itself $\left(\mathrm{IC}_{50}=204 \mathrm{nM}\right)$, along with better in vivo properties (higher stability, imaging signal amplification). These two studies brightly highlight and confirm again the aforementioned positive effect of RGD multivalency on both binding affinity and specificity and imaging signal amplification. 


\subsection{Cyclam, cyclal and phosphatase inhibitors}

Vovk, Kukhar and co-workers reported on the use of 1,4,8,11-tetraazacyclotetradecane (or cyclam) to assemble effective inhibitors of T-cell protein tyrosine phosphatases (TC-PTP), an enzyme involved in the development of type I diabetes. ${ }^{[54]}$ Known TC-PTP inhibitors include aromatic compounds with phosphonic groups, notably $\alpha, \alpha$-difluoro- $\beta$-ketophosphonates that poison the enzyme active site. ${ }^{[55]}$ Cyclam but also cyclen and 1,4,8,12tetraazacyclopentadecane (or cyclal) were used to bring together four ketophosphonate-type arms within a single molecular scaffold (Figure 8). Direct $\mathrm{N}$-alkylation of cyclam with the corresponding $\alpha$, $\alpha$-difluoro- $\beta$-ketophosphonate-functionalized benzyl bromide failed to provide the desired tetra- $N$-substituted derivative in an effective manner (yield $<10 \%$ after purification by column chromatography on silica gel). An alternative procedure involving alkylation of MPA with methyl 3-bromomethylbenzoate, followed by cerium(III)-mediated reaction of ester moieties with $\mathrm{LiCF}_{2} \mathrm{P}(\mathrm{O})(\mathrm{OEt})_{2}$ and final deprotection of phosphonate ethyl esters with bromotrimethylsilane provided the desired multivalent PTP inhibitors in decent overall yields (6-24\% for the three-step procedure). Both the cyclen- (2) and cyclam-based (3) conjugates prove more efficient than the cyclal conjugate $\left(4\right.$, with $\mathrm{IC}_{50}=75,590$ and $91 \mathrm{nM}$ for cyclam-, cyclen- and cyclal-based derivatives, respectively, versus $>100 \mu \mathrm{M}$ for monomeric ketophosphonate used as control), with a better ability to discriminate between various PTP, notably the closely related PTP1B, a negative regulator of insulin signaling (with $\mathrm{IC}_{50}=1.08$, 4.04 and $1.48 \mu \mathrm{M}$ for cyclam-, cyclen- and cyclal-based derivatives, respectively).

\subsection{TACN and DNA junctions}

1,4,7-triazacyclonane (or TACN) was also exploited to benefit from its $C_{3}$-symmetry suited to the construction of chemicals targeting threefold symmetrical targets. Three-way DNA junctions (TWJ) are Y-shaped, higher-order DNA structure at the heart of which a threefold symmetrical cavity is formed (the branch point), ideally suited to accommodate $C_{3^{-}}$ symmetrical ligands. ${ }^{[56]}$ DNA junctions might arise ahead of the replication fork, as a way to relax helical stress that originates in the translocation of the replication machinery along the duplex. If not properly processed (by helicases), these structures act as impediments to DNA transactions, forcing the fork to stall or collapse. ${ }^{[57]}$ Stabilization of TWJ by ad hoc chemicals (TWJ-ligands) is thus a new strategy to create DNA damages and trigger cell death in proliferating cancer cells. ${ }^{[58]}$ A TACN scaffold surrounded by three 2-methylquinoline arms 
(TACN-Q) (Figure 8) was shown to stabilize folded TWJ (evaluated by FRET-melting assay, with $\left.\Delta \mathrm{T}_{1 / 2}=3.8{ }^{\circ} \mathrm{C}\right)^{[59]}$ but, more importantly, promote the formation of TWJ from separated strands (by polyacrylamide gel and TWJ-screen experiments). ${ }^{[60]}$ TACN-Q also exhibit promising anticancer activity $\left(\mathrm{IC}_{50}=10.6 \mu \mathrm{M}\right.$ against melanoma cells $)$.

\section{Conclusions}

Through these selected examples, it is evident that the scope of applications of MPAs goes far beyond the limited roles of complexing agents for metal cations (especially radiometals). As demonstrated here, MPAs are highly versatile molecular tools that prove efficient in many areas, from material science to chemical genetics. Besides their roles as multivalent molecular platforms, MPAs can find other uses that are yet beyond the strict context of this review but are also invaluable to further substantiate their versatility. For instance, different MPA moieties have been incorporated within the core structure of complex bioactive compounds (Figure 9) either as water-solubilizing appendages (which also favors the renal clearance of LLP2 peptide that targets very-late antigen 4 (VLA-4) overexpressed on the surface of cancer cells), ${ }^{[61]}$ or as ATP-binding moieties (both TACN and cyclen were introduced on a dual kinase (EGFR/HER2) inhibitors) ${ }^{[62]}$ in light of pioneering works from Lehn and co-workers on anion receptor polyazamacrocycles. ${ }^{[63]}$ MPAs have also been used for chelating in situ metals: this strategy allows for modulating abnormal metal metabolism such as in Alzheimer's disease in which a high copper concentration triggers neuronal toxicity favoring the formation of pathogenic $\beta$-amyloid plaques and reactive oxygen species (ROS). Derivatives of TACN, ${ }^{[64]}$ of cyclam and cyclen ${ }^{[65]}$ were studied, the latter being conjugated with the $\beta$-sheet breaker KLVFF peptide ${ }^{[66]}$ or with silica nanoparticles. ${ }^{[67]}$

MPAs have also been embedded as bioactive components per se, the most brilliant example being certainly AMD3100: ${ }^{[68]}$ this bis-cyclam derivative is used as an antagonist of CXCR4 receptors, initially developed as an anti-HIV agent and subsequently repurposed for the mobilization of hematopoietic stem cells in cancer patients, now commercialized as Mozobil $^{\circledR}$ (plerixafor). ${ }^{[69]}$ AMD3100 was also studied for its ability to alter the copper metabolism in Alzheimer's disease (vide supra) ${ }^{[70]}$ and as possible anti-malaria agent. ${ }^{[71]}$ To improve the pharmacological properties of AMD3100, many derivatives have been designed and synthesized (Figure 9), in which the core structure of cyclam was changed for 1,4-dioxaor 1,4-dithia-8,11-diazacyclotetradecane, ${ }^{[72]}$ or for side- or cross-bridged cyclams ${ }^{[73]}$ (also used 
for building original antimalarial agents ${ }^{[74]}$ thus expanding the chemistry of MPAs. Similarly, cyclen- and cyclam-based MPAs were investigated to fight against the parasitic diseases leishmaniasis, and it was found that 2 metal complexes (out of 44 tested compounds), i.e., the iron(II) and manganese(II) complexes of a bisbenzylcyclen derivative, displayed the most promising properties as antileishmanial agents. ${ }^{[75]}$
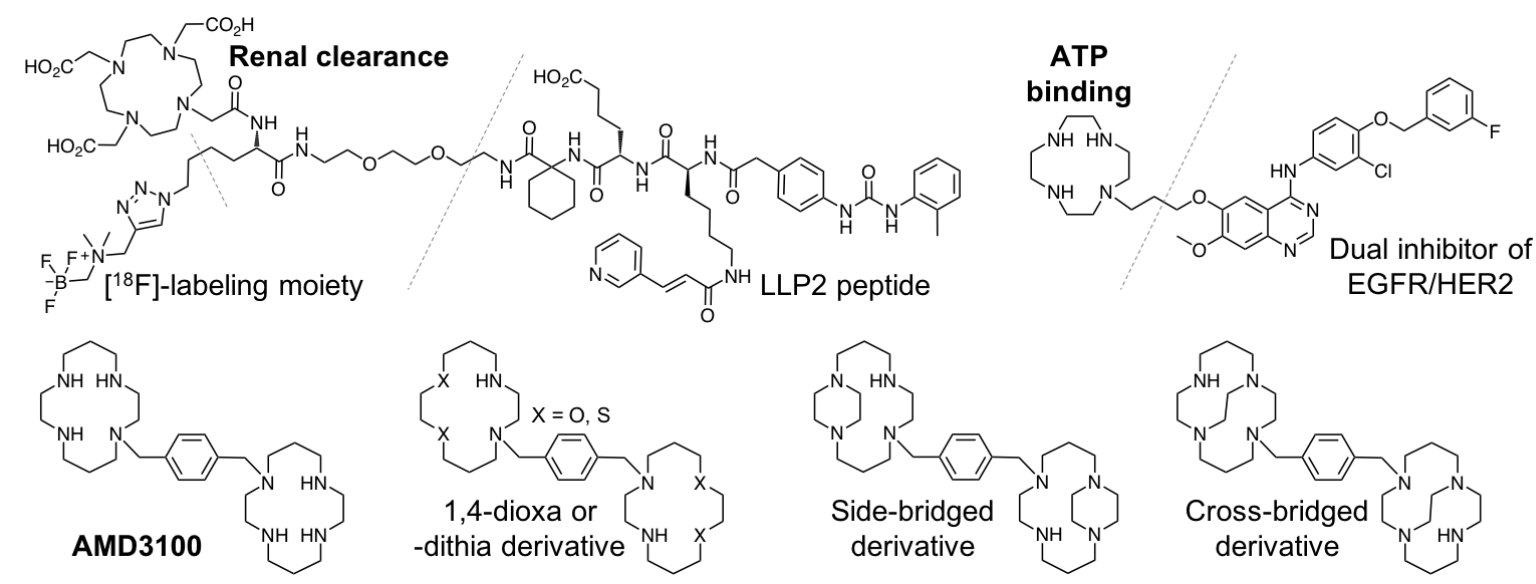

Figure 9. Selected examples of compounds bearing one or two MPAs that behave as bioactive moieties per se.

These examples further nurture the view whereby MPAs are far more versatile than initially anticipated. We are convinced that the best is still to come, with new generations of chemists eager and poised to decompartmentalize chemical fields to make the best use of the portfolio of advanced molecular tools at their disposal. This will provide genuine new opportunities and open brand new chemical landscapes that are still, at present, beyond imagining.

Acknowledgements. The authors thank the CNRS and the Université Bourgogne FrancheComté (UBFC) for funding, along with the Agence Nationale de la Recherche (ANR) and the European Research Council (ERC) for grants ID ANR-17-CE17-0010-01 and H2020-MSCA-IF2016-750368, respectively. This work belongs to the Pharmacoimagerie \& agents théranostiques project supported by the Université de Bourgogne and Conseil Régional de Bourgogne (PARI) and the European Union (PO FEDER-FSE Bourgogne 2014/2020 programs). The authors also warmly thank their colleagues at the ICMUB and CheMatech ${ }^{\mathrm{TM}}$ company for stimulating daily discussions, and all scientists worldwide involved in this area to make it a lively field of research (our apologies for any possible omissions). 


\section{References}

[1] P. Rigo, P. Paulus, B. Kaschten, R. Hustinx, T. Bury, G. Jerusalem, T. Benoit, J. FoidartWillems, Eur. J. Nucl. Med. 1996, 23, 1641-1674.

[2] I. R. Vlahov, C. P. Leamon, Bioconjugate Chem. 2012, 23, 1357-1369.

[3] For selected reviews about the chemistry of MPAs, see: a) X. Yu, J. Zhang, Macrocyclic Polyamines: Synthesis and Applications, Wiley-VCH, Weinheim, 2018; b) F. Denat, S. Brandès, R. Guilard, Synlett 2000, 561-574; c) J. A. Bender, N. A. Meanwell, T. Wang, Tetrahedron 2002, 58, 3111-3128; d) M. Suchy, R. H. E. Hudson, Eur. J. Org. Chem. 2008, 4847-4865; e) N. Cakic, S. Guenduez, R. Rengarasu, G. Angelovski, Tetrahedron Lett. 2015, 56, 759-765.

[4] R. E. Mewis, S. J. Archibald, Coord. Chem. Rev. 2010, 254, 1686-1712.

[5] H. Stetter, W. Frank, Angew. Chem. Int. Ed. 1976, 15, 686-686.

[6] J. Wahsner, E. M. Gale, A. Rodríguez-Rodríguez, P. Caravan, Chem. Rev. 2018, 119, 9571057.

[7] a) G. J. Stasiuk, N. J. Long, Chem. Commun. 2013, 49, 2732-2746; b) C. S. Cutler, H. M. Hennkens, N. Sisay, S. Huclier-Markai, S. S. Jurisson, Chem. Rev. 2013, 113, 858-883.

[8] S. N. M. Chilla, C. Henoumont, L. Vander Elst, R. N. Muller, S. Laurent, Isr. J. Chem. 2017, $57,800-808$.

[9] a) S. M. Larson, J. A. Carrasquillo, N. K. Cheung, O. W. Press, Nat. Rev. Cancer 2015, 15, 347-360; b) K. L. Chatalic, D. J. Kwekkeboom, M. de Jong, J. Nucl. Med. 2015, 56, 18091812; c) M. Fani, H. R. Maecke, Eur. J. Nucl. Med. Mol. Imaging 2012, 39, S11-30; d) V. Ambrosini, M. Fani, S. Fanti, F. Forrer, H. R. Maecke, J. Nucl. Med. 2011, 52, 42S-55S; e) M. M. Graham, Y. Menda, J. Nucl. Med. 2011, 52 Suppl 2, 56S-63S.

[10] a) S. Viswanathan, Z. Kovacs, K. N. Green, S. J. Ratnakar, A. D. Sherry, Chem. Rev. 2010, 110, 2960-3018; b) C. S. Cutler, H. M. Hennkens, N. Sisay, S. Huclier-Markai, S. S. Jurisson, Chem. Rev. 2012, 113, 858-883; c) M. C. Heffern, L. M. Matosziuk, T. J. Meade, Chem. Rev. 2013, 114, 4496-4539; d) M. R. Gill, N. Falzone, Y. Du, K. A. Vallis, Lancet Oncol. 2017, 18, e414-e423; e) S. M. Pinto, V. Tomé, M. J. Calvete, M. M. C. Castro, É. Tóth, C. F. Geraldes, Coord. Chem. Rev. 2019, 390, 1-31; f) T. J. Clough, L. Jiang, K.-L. Wong, N. J. Long, Nat. Commun. 2019, 10, 1420.

[11] S. Shinoda, T. Okazaki, T. Nishimura, K. Hori, H. Tsukube, Chem. Commun. 2001, 976977.

[12] S. Shinoda, T. Okazaki, T. N. Player, H. Misaki, K. Hori, H. Tsukube, J. Org. Chem. 2005, 70, 1835-1843.

[13] T. Michinobu, S. Shinoda, T. Nakanishi, J. P. Hill, K. Fujii, T. N. Player, H. Tsukube, K. Ariga, J. Am. Chem. Soc. 2006, 128, 14478-14479.

[14] a) K. C. Tjandra, P. Thordarson, Bioconjugate Chem. 2019; b) H. L. Handl, J. Vagner, H. Han, E. Mash, V. J. Hruby, R. J. Gillies, Exp. Opin. Ther. Targets 2004, 8, 565-586; c) H. J. Wester, H. Kessler, J. Nucl. Med. 2005, 46, 1940-1945.

[15] a) P. C. Brooks, R. A. Clark, D. A. Cheresh, Science 1994, 264, 569-571; b) S. Zitzmann, V. Ehemann, M. Schwab, Cancer Res. 2002, 62, 5139-5143; c) U. Hersel, C. Dahmen, H. Kessler, Biomaterials 2003, 24, 4385-4415; dM. D. Pierschbacher, E. Ruoslahti, Nature 1984, 309, 30. 
[16] a) J. D. Hood, D. A. Cheresh, Nat. Rev. Cancer 2002, 2, 91-100; b) P. C. Brooks, A. M. Montgomery, M. Rosenfeld, R. A. Reisfeld, T. Hu, G. Klier, D. A. Cheresh, Cell 1994, 79, 1157-1164; c) D. Cox, M. Brennan, N. Moran, Nat. Rev. Drug Discov. 2010, 9, 804-820.

[17] a) W. M. Isenberg, R. P. McEver, D. R. Phillips, M. A. Shuman, D. F. Bainton, J. Cell. Biol. 1987, 104, 1655-1663; b) T. Hato, N. Pampori, S. J. Shattil, J. Cell. Biol. 1998, 141, 16851695; c) G. Maheshwari, G. Brown, D. A. Lauffenburger, A. Wells, L. G. Griffith, J. Cell. Sci. 2000, 113 1677-1686.

[18] S. Liu, Bioconjugate Chem. 2009, 20, 2199-2213.

[19] E. Garanger, D. Boturyn, Z. Jin, P. Dumy, M. C. Favrot, J. L. Coll, Mol. Ther. 2005, 12, 11681175.

[20] X. Zhang, H. Liu, Z. Miao, R. Kimura, F. Fan, Z. Cheng, Bioorg. Med. Chem. Lett. 2011, 21, 3423-3426.

[21] G. Hao, X. Sun, Q. N. Do, B. Ocampo-Garcia, A. Vilchis-Juarez, G. Ferro-Flores, L. M. De Leon-Rodriguez, Dalton Trans. 2012, 41, 14051-14054.

[22] J. Šimeček, P. Hermann, J. Havlíčková, E. Herdtweck, T. G. Kapp, N. Engelbogen, H. Kessler, H. J. Wester, J. Notni, Chem. Eur. J. 2013, 19, 7748-7757.

[23] P. Thirumurugan, D. Matosiuk, K. Jozwiak, Chem. Rev. 2013, 113, 4905-4979.

[24] M. F. Debets, S. S. van Berkel, J. Dommerholt, A. J. Dirks, F. P. J. T. Rutjes, F. L. van Delft, Acc. Chem. Res. 2011, 44, 805-815.

[25] a) D. A. Silver, I. Pellicer, W. R. Fair, W. Heston, C. Cordon-Cardo, Clin. Cancer Res. 1997, 3, 81-85; b) US National Library of Medicine, 2019, June 04 (https://clinicaltrials.gov).

[26] A. Wurzer, A. Vágner, D. Horváth, F. Fellegi, H.-J. Wester, F. Kálmán, J. Notni, Front. Chem. 2018, 6, Article ID: 107.

[27] a) S. Burge, G. N. Parkinson, P. Hazel, A. K. Todd, S. Neidle, Nucleic Acids Res. 2006, 34, 5402-5415; b) G. W. Collie, G. N. Parkinson, Chem. Soc. Rev. 2011, 40, 5867-5892.

[28] a) D. Rhodes, H. J. Lipps, Nucleic Acids Res. 2015, 43, 8627-8637; b) R. Hänsel-Hertsch, M. Di Antonio, S. Balasubramanian, Nat. Rev. Mol. Cell Biol. 2017, 18, 279; c) S. Balasubramanian, L. H. Hurley, S. Neidle, Nat. Rev. Drug Discov. 2011, 10, 261-275.

[29] a) S. Neidle, J. Med. Chem. 2016; b) D. Monchaud, M.-P. Teulade-Fichou, Org. Biomol. Chem. 2008, 6, 627-636; c) S. M. Haider, S. Neidle, G. N. Parkinson, Biochimie 2011, 93, $1239-1251$.

[30] a) L. Stefan, A. Guedin, S. Amrane, N. Smith, F. Denat, J.-L. Mergny, D. Monchaud, Chem. Commun. 2011, 47, 4992-4994 b) D. Monchaud in DNA in Supramolecular Chemistry and Nanotechnology (Eds. E. Stulz, G. H. Clever), John Wiley \& Sons, Ltd., 2015, pp 229-246.

[31] a) R. Haudecoeur, L. Stefan, F. Denat, D. Monchaud, J. Am. Chem. Soc. 2013, 135, 550553; b) R. Haudecoeur, L. Stefan, D. Monchaud, Chem. Eur. J. 2013, 19, 12739-12747.

[32] H.-Y. Hu, N.-H. Lim, D. Ding-Pfennigdorff, J. Saas, K. U. Wendt, O. Ritzeler, H. Nagase, O. Plettenburg, C. Schultz, M. Nazare, Bioconjugate Chem. 2015, 26, 383-388.

[33] J. Dingle, A. Barrett, A. Poole, P. Stovin, Biochem. J. 1972, 127, 443-444.

[34] K. Ferreira, H. Y. Hu, V. Fetz, H. Prochnow, B. Rais, P. P. Müller, M. Brönstrup, Angew. Chem. Int. Ed. 2017, 56, 8272-8276.

[35] S. C. Andrews, A. K. Robinson, F. Rodríguez-Quiñones, FEMS Microbiol. Rev. 2003, 27, 215-237.

[36] Y. Rousselin, N. Sok, F. Boschetti, R. Guilard, F. Denat, Eur. J. Org. Chem. 2010, 16881693. 
[37] A. Laguerre, M. Levillain, L. Stefan, R. Haudecoeur, F. Katranji, M. Pirrotta, D. Monchaud, Chimia 2015, 69, 530-536.

[38] I. Renard, M. Grandmougin, A. Roux, S. Y. Yang, P. Lejault, M. Pirrotta, J. M. Y. Wong, D. Monchaud, Nucleic Acids Res. 2019, 47, 5502-5510.

[39] S. Y. Yang, P. Lejault, S. Chevrier, R. Boidot, A. G. Robertson, J. M. Wong, D. Monchaud, Nat. Commun. 2018, 9, 4730.

[40] a) L. Anders, M. G. Guenther, J. Qi, Z. P. Fan, J. J. Marineau, P. B. Rahl, J. Loven, A. A. Sigova, W. B. Smith, T. I. Lee, Nat. Biotechnol. 2014, 32, 92; b) R. Rodriguez, K. M. Miller, Nat. Rev. Genet. 2014, 15, 783-796.

[41] Y.-M. Zhang, Z. Huang, J. Zhang, W.-X. Wu, Y.-H. Liu, X.-Q. Yu, Biomater. Sci. 2017, 5, 718729.

[42] J.-P. Behr, Chimia 1997, 51, 34-36.

[43] a) Q.-D. Huang, G.-X. Zhong, Y. Zhang, J. Ren, Y. Fu, J. Zhang, W. Zhu, X.-Q. Yu, PLoS One 2011, 6, e23134; b) Q.-D. Huang, J. Ren, H. Chen, W.-J. Ou, J. Zhang, Y. Fu, W. Zhu, X.-Q. Yu, ChemPlusChem 2012, 77, 584-591; c) B.-Q. Liu, W.-J. Yi, J. Zhang, Q. Liu, Y.-H. Liu, S.D. Fan, X.-Q. Yu, Org. Biomol. Chem. 2014, 12, 3484-3492.

[44] Y.-G. Gao, U. Alam, A.-X. Ding, Q. Tang, Z.-L. Tan, Y.-D. Shi, Z.-L. Lu, A.-R. Qian, Bioorg. Chem. 2018, 79, 334-340.

[45] Y.-M. Zhang, Z. Huang, X.-R. Wu, J. Zhang, Y.-H. Liu, X.-Q. Yu, ACS Appl. Nano Mater. 2018, 1, 3925-3934.

[46] J. Singh, D. Lopes, D. Gomika Udugamasooriya, Pept. Sci. 2016, 106, 673-684.

[47] F. Wojciechowski, M. Suchy, A. X. Li, H. A. Azab, R. Bartha, R. H. Hudson, Bioconjugate Chem. 2007, 18, 1625-1636.

[48] M. Suchý, R. H. Hudson, Synlett 2012, 23, 893-896.

[49] M. Suchý, M. Milne, A. X. Li, N. McVicar, D. W. Dodd, R. Bartha, R. H. Hudson, Eur. J. Org. Chem. 2011, 6532-6543.

[50] P. Thuéry, CrystEngComm 2008, 10, 808-810.

[51] Z. Shen, C. Zhang, X. Yu, J. Li, Z. Wang, Z. Zhang, B. Liu, J. Mater. Chem. C 2018, 6, 96369641.

[52] S. Liu, D. Li, C.-W. Huang, L.-P. Yap, R. Park, H. Shan, Z. Li, P. S. Conti, Theranostics 2012, 2, 589-596.

[53] A. N. Singh, W. Liu, G. Hao, A. Kumar, A. Gupta, O. K. Oz, J.-T. Hsieh, X. Sun, Bioconjugate Chem. 2011, 22, 1650-1662.

[54] O. L. Kobzar, M. V. Shevchuk, A. N. Lyashenko, V. Y. Tanchuk, V. D. Romanenko, S. M. Kobelev, A. D. Averin, I. P. Beletskaya, A. I. Vovk, V. P. Kukhar, Org. Biomol. Chem. 2015, $13,7437-7444$.

[55] V. V. Vintonyak, A. P. Antonchick, D. Rauh, H. Waldmann, Curr. Opin. Chem. Biol. 2009, 13, 272-283.

[56] A. Oleksi, A. G. Blanco, R. Boer, I. Usón, J. Aymamí, A. Rodger, M. J. Hannon, M. Coll, Angew. Chem. Int. Ed. 2006, 45, 1227-1231.

[57] a) E. V. Mirkin, S. M. Mirkin, Microbiol. Mol. Biol. Rev. 2007, 71, 13-35; b) G. Wang, K. M. Vasquez, Mutat. Res. 2006, 598, 103-119.

[58] K. Duskova, J. Lamarche, S. Amor, C. Caron, N. Queyriaux, M. Gaschard, M.-J. Penouilh, G. De Robillard, D. Delmas, C. H. Devillers, A. Granzhan, M.-P. Teulade-Fichou, M. 
Chavarot-Kerlidou, B. Therrien, S. Britton, D. Monchaud, J. Med. Chem. 2019, 62, 44564466.

[59] J. Novotna, A. Laguerre, A. Granzhan, M. Pirrotta, M.-P. Teulade-Fichou, D. Monchaud, Org. Biomol. Chem. 2015, 13, 215-222.

[60] L. Guyon, M. Pirrotta, K. Duskova, A. Granzhan, M.-P. Teulade-Fichou, D. Monchaud, Nucleic Acids Res. 2018, 46, e16.

[61] A. Roxin, C. Zhang, S. Huh, M. L. Lepage, Z. Zhang, K.-S. Lin, F. Bénard, D. M. Perrin, Bioconjugate Chem. 2019, 30, 1210-1219.

[62] Y. Ju, J. Wu, X. Yuan, L. Zhao, G. Zhang, C. Li, R. Qiao, J. Med. Chem. 2018, 61, 1137211383.

[63] B. Dietrich, M. W. Hosseini, J. M. Lehn, R. B. Sessions, J. Am. Chem. Soc. 1981, 103, 12821283.

[64] H.-F. Ji, H.-Y. Zhang, Bioorg. Med. Chem. Lett. 2005, 15, 21-24.

[65] a) T. Chen, X. Wang, Y. He, C. Zhang, Z. Wu, K. Liao, J. Wang, Z. Guo, Inorg. Chem. 2009, 48, 5801-5809; b) P. Gonzales, V. C. P. da Costa, K. Hyde, Q. Wu, O. Annunziata, J. Rizo, G. Akkaraju, K. N. Green, Metallomics 2014, 6, 2072-2082; c) M. El Safadi, M. Bhadbhade, R. Shimmon, A. T. Baker, A. M. McDonagh, Inorg. Chim. Acta 2017, 467, 343-350; d) A. Conte-Daban, M. Beyler, R. Tripier, C. Hureau, Chem. Eur. J. 2018, 24, 8447-8452.

[66] W.-h. Wu, P. Lei, Q. Liu, J. Hu, A. P. Gunn, M.-s. Chen, Y.-f. Rui, X.-y. Su, Z.-p. Xie, Y.-F. Zhao, A. I. Bush, Y.-m. Li, J. Biol. Chem. 2008, 283, 31657-31664.

[67] J. Wang, K. Wang, Z. Zhu, Y. He, C. Zhang, Z. Guo, X. Wang, RSC Adv. 2019, 9, 1412614131.

[68] G. A. Donzella, D. Schols, S. W. Lin, J. A. Esté, K. A. Nagashima, P. J. Maddon, G. P. Allaway, T. P. Sakmar, G. Henson, E. DeClercq, Nat. Med. 1998, 4, 72.

[69] E. De Clercq, Antivir. Chem. Chemother. 2019, 27, DOI: 10.1177/2040206619829382.

[70] V. Moret, Y. Laras, N. Pietrancosta, C. Garino, G. Quéléver, A. Rolland, B. Mallet, J.-C. Norreel, J.-L. Kraus, Bioorg. Med. Chem. Lett. 2006, 16, 3298-3301.

[71] A. Abiri, Med. Hypotheses 2018, 118, 68-73.

[72] G. J. Bridger, R. T. Skerlj, S. Padmanabhan, S. A. Martellucci, G. W. Henson, S. Struyf, M. Witvrouw, D. Schols, E. De Clercq, J. Med. Chem. 1999, 42, 3971-3981.

[73] G. C. Valks, G. McRobbie, E. A. Lewis, T. J. Hubin, T. M. Hunter, P. J. Sadler, C. Pannecouque, E. De Clercq, S. J. Archibald, J. Med. Chem. 2006, 49, 6162-6165.

[74] P. N. A. Amoyaw, K. Pham, A. N. Cain, J. M. McClain, T. J. Hubin, M. O. Faruk Khan, Curr. Org. Synth. 2014, 11, 916-921.

[75] T. J. Hubin, A. N. Walker, D. J. Davilla, T. N. Carder Freeman, B. M. Epley, T. R. Hasley, P. N. A. Amoyaw, S. Jain, S. J. Archibald, T. J. Prior, J. A. Krause, A. G. Oliver, B. L. Tekwani, M. O. F. Khan, Polyhedron 2019, 163, 42-53. 


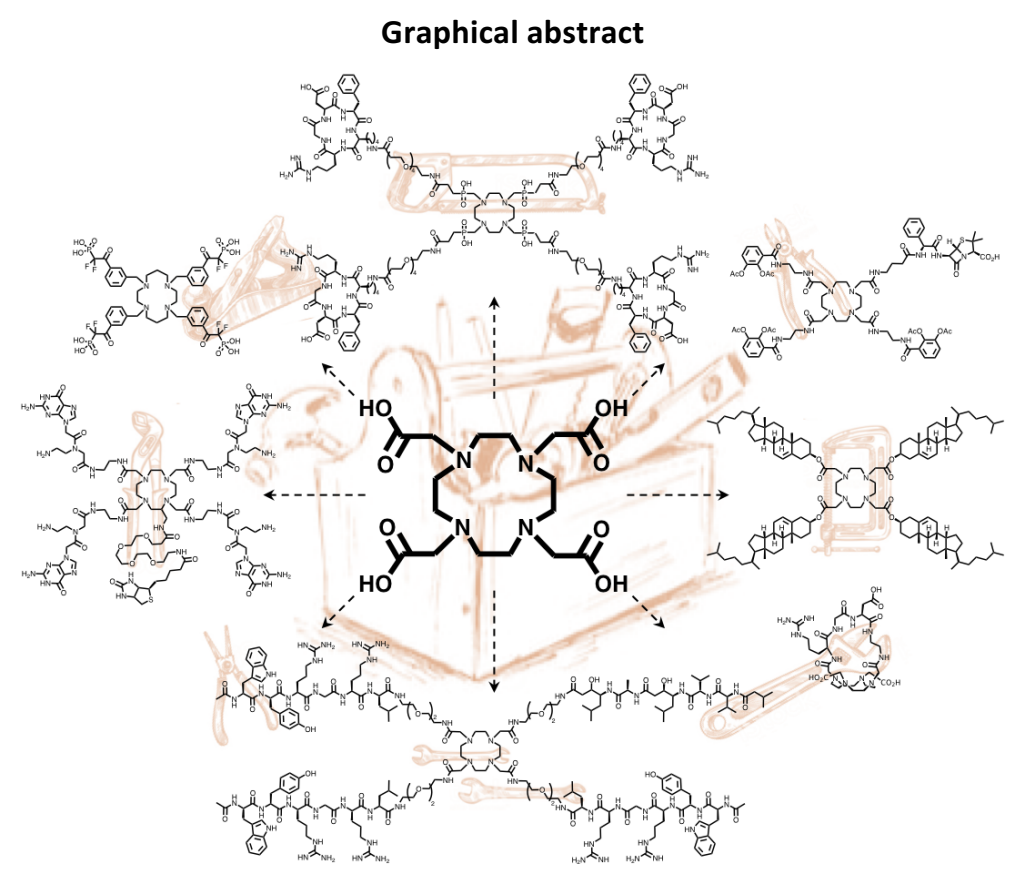

No metal, no cry! Macrocyclic polyamines (MPAs) are important chelating agents for cations, anions and neutral molecules. Most common compounds such as cyclen and DOTA are inseparable from great advances in the field of contrast agents for magnetic resonance or PET/SPECT imaging. Their unique topological and physicochemical properties make them also attractive multivalent molecular platforms for applications that go far beyond the conventional metal chelation. The key topics discussed in this review are the use of MPAs as molecular platforms for applications in material chemistry, medicinal chemistry and chemical biology. 


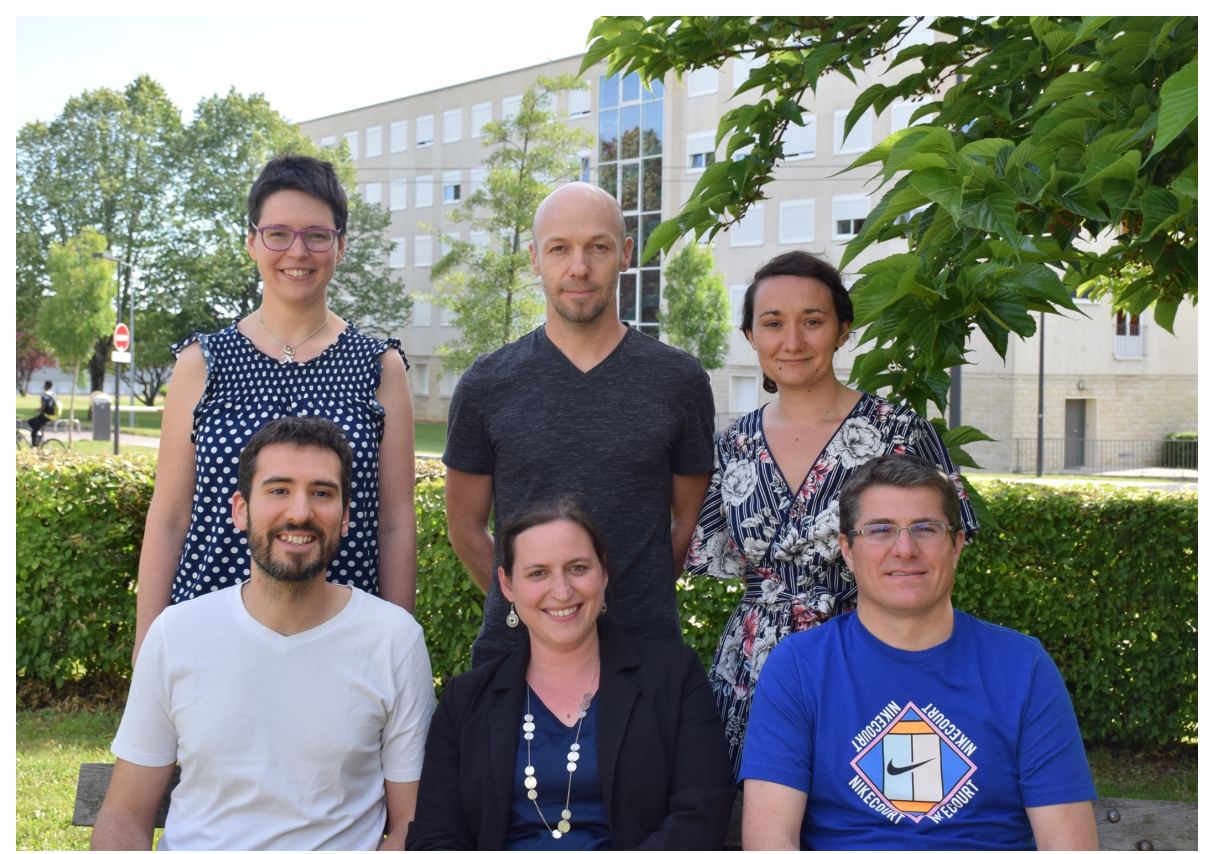

Upper row, from left to right: Katerina Duskova, David Monchaud \& Pauline Lejault Lower row, from left to right: Ibai Valverde, Claire Bernhard \& Anthony Romieu

Dr. Pauline Lejault received her PhD in biochemistry in 2017 from the Natural History Museum (Paris, France) under the supervision of Drs. Jean François Riou and Anthony Bugaut. She joined the group of Dr. David Monchaud at the Institut de Chimie Moléculaire de l'Université de Bourgogne (ICMUB, Dijon, France) for a first post-doctoral position currently focused on G-quadruplex DNA/RNA targeting for identifying small molecules with G4-resolving capabilities.

Dr. Katerina Duskova received her PhD in medicinal chemistry in 2016 at the University of Alcala (Spain) under the supervision of Drs. Lourdes Gude and María José Fernández. In 2017, she joined David Monchaud research group at the Institut de Chimie Moléculaire de I'Université de Bourgogne (ICMUB, Dijon, France) as a H2020MSCA post-doctoral researcher to study alternative DNA secondary structure ligands as novel anticancer drugs.

Dr. Claire Bernhard received her PhD in chemistry in 2011 from the University of Dijon (France) under the supervision of Dr. Christine Goze and Pr. Franck Denat. After 5 years of professional experiences as engineer specialized in the development of innovative tools for molecular imaging (research and project management), she was appointed CNRS research engineer in 2016 (ICMUB, Dijon, France) and is currently in charge of technology transfer and valorization aspects.

Dr. Ibai Valverde received his PhD in chemistry in 2010 at the University of Orléans (France) under the supervision of Drs. Agnès Delmas and Vincent Aucagne. After a postdoctoral stay at the division of radiopharmaceutical chemistry of the University of Basel Hospital (Basel, Switzerland), he was appointed CNRS researcher in 2016 and moved to the Institut de Chimie Moléculaire de l'Université de Bourgogne (ICMUB, Dijon, France). His research interests focus on finding tumor targeting systems mainly based on peptides and small molecules, bionconjugation techniques, and reporter probes for in vivo imaging.

Prof. Anthony Romieu received his Ph.D. in organic chemistry in 1999 at the University Joseph Fourier (Grenoble, France) under the supervision of Drs. Jean Cadet and Didier Gasparutto (Laboratory of Nucleic Acids Damages, CEA-Grenoble). After several professional experiences as CNRS engineer, senior scientist in a Swiss private biotech company and lecturer at the University of Rouen, he was appointed professor in 2013 at the University of Burgundy (Dijon, France). He also joined the ICMUB laboratory and his current research interests mainly focus on the development of advanced chemical tools for biosensing and bioimaging applications.

Dr. David Monchaud received his Ph.D. in chemistry 2002 at the University of Geneva (Switzerland) under the supervision of prof. Jérôme Lacour. After two post-docs in Paris (France), he was appointed as a CNRS researcher in 2005 in the laboratory of Prof. Jean-Marie Lehn (College de France, Paris) under the supervision of Dr. MariePaule Teulade-Fichou, before moving to Institut Curie (Orsay) in 2007 with Dr. Teulade-Fichou, and to the Institut de Chimie Moléculaire de l'Université de Bourgogne (ICMUB, Dijon, France) in 2009, to develop chemical genetics programs on DNA/RNA secondary structures, smart ligands and probes. 